\title{
Isotopes in Hydrology and Hydrogeology
}

\author{
Maurizio Barbieri ${ }^{(0)}$ \\ Department of Earth Sciences, Sapienza University of Rome, Piazzale Aldo Moro 5, 00185 Roma, Italy; \\ maurizio.barbieri@uniroma1.it
}

Received: 29 January 2019; Accepted: 5 February 2019; Published: 7 February 2019

\begin{abstract}
The structure, status, and processes of the groundwater system, which can only be acquired through scientific research efforts, are critical aspects of water resource management. Isotope hydrology and hydrogeology is a genuinely interdisciplinary science. It developed from the application of methods evolved in physics (analytical techniques) to problems of Earth and the environmental sciences since around the 1950s. In this regard, starting from hydrogeochemical data, stable and radioactive isotope data provide essential tools in support of water resource management. The inventory of stable isotopes, which has significant implications for water resources management, has grown in recent years. Methodologies based on the use of isotopes in a full spectrum of hydrological problems encountered in water resource assessment, development, and management activities are already scientifically established and are an integral part of many water resource investigations and environmental studies. The driving force behind this Special Issue was the need to point the hydrological and water resource management societies in the direction of up-to-date research and best practices.
\end{abstract}

Keywords: stable isotopes; radioactive isotopes; lake; river; groundwater; water resource systems; water resources management

\section{Introduction}

The increasing worldwide pressure on water resources, under natural and anthropogenic conditions-including climatic change-requires an aggressive integrated multidisciplinary approach to address the scientific and societal issues involving water resources.

The structure, status, and processes of the groundwater system, which can only be acquired through scientific research efforts, are critical aspects of water resource management. In this regard, hydrogeochemical data as well as stable and radioactive isotope data provide essential tools in support of water resources management.

Hence, there is a need for a close investigation of water science and policy "at the margins". We need to know what happens at the interfaces of surface water and groundwater, as well as freshwater and saltwater, at global and watershed scales. Phenomena and possible changes are to be studied by simultaneously addressing the quantity and quality, science and policy, and water and civilization aspects.

Many of the present-day methodologies in water science have been developed with limited data and data processing procedures. Due to the growth and improvement of modern technologies, a new generation of data has been made available to water resource management, which have a much higher spatial and temporal resolution.

Furthermore, information technology development now provides access to a higher level of computational capability, which calls for a re-examination of basic concepts for better diversification of models for various uses.

Within the environmental sciences, the application of isotope methodology is being used to an ever-increasing extent. 
An application of this includes tracing the evolution of a water mass from its origin as precipitation, through its recharge processes, and ending at its appearance in an aquifer. There is a particular focus on the operations at the surface-atmosphere and land-biosphere-atmosphere interfaces, since these are the sites of significant changes in isotope composition.

Besides this, isotopes can be used to determine the origin of specific solutes in groundwater. This type of application commonly involves stable isotopes. The inventory of stable isotopes, which has significant implications for water resource management, has grown in recent years. The other main class of isotope applications was derived from the decay of radioisotopes. Unlike stable isotope applications that shed light on geochemical evolution in aquifers, radioisotopes are primarily used to define the relative or absolute age of water in an aquifer. The date obtained gives some evidence of the residence time of water in an aquifer once it has passed through the vadose zone. Besides this, isotope analyses can test and fine-tune a conceptual hydrogeological model.

Methodologies based on the use of isotopes in a full spectrum of hydrological problems encountered in water resource assessment, development, and management activities are already scientifically established and are an integral part of many water resource investigations and environmental studies. The concept of "Tracing" is applied for these methodologies, in which either naturally occurring isotopic species (environmental isotopes) or intentionally introduced tracers are employed. In the last decades, there has been an increasing interest in environmentally friendly tracers (e.g., isotopes), because a concern has emerged about the application of artificial tracers in aquatic ecosystems due to their potentially negative impact on the environment.

A variety of well-established and field-verified isotopic techniques offer useful tools, with proven technological and economic benefits for water resource assessment, development, and management. It is important to note that isotope studies are not expensive and that a single analysis can yield a considerable amount of information on the hydrological process, as compared to costlier classical investigations. Recent overviews [1,2] have highlighted how some isotope systematics have now become well-established, especially in areas characterized by natural and anthropogenic input and its potential as a tool for monitoring and environmental planning.

Therefore, this Special Issue aims to advertise and mainly deal with findings on the robustness or fitness-for-purpose regarding the relevance and use of isotopes in water resource systems, with respect to approaching problems and opportunities scientifically. Original research papers were selected by a peer-review process with the purpose of rapid, accessible, and wide dissemination of results.

\section{Contributions}

In this section, the selected papers presented in the Special Issue are highlighted. They fall broadly into three categories: First, stable oxygen, hydrogen, and carbon isotopes, as well as the radioactive tritium to understand the hydrological process, to characterize its source(s), its fractionation effects, and dating groundwater systems (ten papers). Second, those focused on the use of other stable isotopes to define the sources and mixing relationships in geochemical studies (four papers). Finally, those using the multi-isotope approach to tracing pollution and its sources (five papers).

\subsection{Stable Oxygen, Hydrogen, and Carbon-Isotopes}

Nine articles [3-11] look at the start of the hydrological cycle and its processes (including lake water balance), and at the origin of rainfall and its selection in groundwater recharge using characteristic, naturally occurring $\delta^{2} \mathrm{H}$ and $\delta^{18} \mathrm{O}$ signatures. Spatial and temporal modifications in hydrogen and oxygen isotopic compositions $\left(\delta^{2} \mathrm{H}\right.$ and $\left.\delta^{18} \mathrm{O}\right)$ could be associated to equilibrium exchanges occurring at all phase transitions and kinetic isotopic fractionation during the transformation from the ocean surface to the atmosphere, small rainfall amounts when raindrops fall below the cloud [3]. In particular, based on the data of water stable isotopes $\left(\delta^{2} \mathrm{H}\right.$ and $\left.\delta^{18} \mathrm{O}\right)$ in the Naqu River basin (China), Chen et al. [3] developed a framework of the variable fuzzy evaluation model (VFEM) to provide a method to classify stable isotopes and to generalize the source identification of water 
replenishment by rainfall or snowmelt in a river basin. Mahindawansha et al. [4] propose an automatic sampling system for high-resolution data on stable isotopes of water $\left(\delta^{2} \mathrm{H}\right.$ and $\left.\delta^{18} \mathrm{O}\right)$ to investigate multiple rice-based cropping systems in Los Baños, Laguna (Philippines). Results show that, under dry conditions, there is a clear and distinguishable crop effect on isotopic composition in groundwater. Peters et al. [5] apply several geochemical and isotopic tracer methods to further the understanding of recharge and groundwater flow on Mount Shasta (4322 m), a strato-volcano in the Cascade Range of California (USA).

Guo et al. [6] employ major ions and selected environmental tracers $\left(\delta^{2} \mathrm{H}\right.$ and $\delta^{18} \mathrm{O},{ }^{3} \mathrm{H}$ and chlorofluorocarbons (CFCs)) to determine the source, flow rates, and hydrochemical evolution of groundwater in an alluvial fan along the front of the Qilian Mountains, which serves as an essential groundwater reservoir in Northwest China.

The use of the isotope technique is of high importance for understanding the hydrologic balance of lakes and regional hydrologic cycles. Shi et al. [7] report stable isotope compositions of lake and source water in a typical monsoonal temperate glacier region in China (Lashi Lake basin). The results provide a reference for the long-term monitoring and modeling of the hydrology processes of the basin, and are essential for the regional water resource. Gao et al. [8] use multiple tracers (chloride, $\delta^{18} \mathrm{O}$, and $\delta^{2} \mathrm{H}$ in water) approaches in Hulun Lake, located in a remote, semi-arid area in the Northeastern part of Inner Mongolia, China. The chloride mass balance inferred that groundwater currently contributes more than $90 \%$ of the annual chloride loading to the lake, which is likely four times greater than the earlier period (1981-2000) with a lower groundwater input. Maruyama and Kato [9] examined the oxygen and hydrogen isotopic ratios of surface and groundwater in the catchment of Laguna Lake, Republic of the Philippines, to identify the types of water that combine and control these ratios in the lake water.

Yang and Li [10] investigate the Mafengou River basin, a cold alpine region in the Qilian mountainous area in China. The results show that there was no significant difference in the chemical water characteristics of various water bodies, and no apparent temporal variation, but they exhibited spatial variation.

González-Trinidad et al. [11] emphasize the use of stable environmental isotopes in an alluvial aquifer in arid and semiarid regions of Mexico.

The last contribution to this section is related to the geothermal system [12]. Wang et al. [12] discuss the evolutionary process of geothermal water in Henan province (North China Plain). Through a conventional water chemical group, hydrogen and oxygen isotopes $\left(\delta^{2} \mathrm{H}\right.$ and $\left.\delta^{18} \mathrm{O}\right)$, dissolved inorganic carbon (DIC), and associated isotopes $\left(\delta^{13} \mathrm{C}_{\mathrm{DIC}}\right)$, authors demonstrate that the primary source of DIC in geothermal water is $\mathrm{CO}_{2}$, which has a biological origin in soils, as well as the dissolution of carbonate minerals in surrounding rocks. Thus, as the depth increases, the contribution of soil biogenic carbon sources to DIC decreases, while the influence of carbonate dissolution on DIC increases. These results are helpful in solving the contradiction between geothermal water development and protection, and for providing an essential reference for the development and utilization of geothermal in the North Cina Plain.

\subsection{Multi-Isotope Studies $\left({ }^{87} \mathrm{Sr} /{ }^{\beta 6} \mathrm{Sr},{ }^{222} \mathrm{Rn}\right.$, and $\left.\delta^{34} \mathrm{~S}\right)$}

The applications of the stable isotopes of strontium $\left({ }^{87} \mathrm{Sr} /{ }^{86} \mathrm{Sr}\right.$ isotopic ratio) are becoming increasingly important in studies of surface and groundwater systems, including the identification of saline sources. Unlike the stable isotopes of oxygen and hydrogen, $\mathrm{Sr}$ isotopes do not measurably fractionate in nature. Instead, the proportion of radiogenic ${ }^{87} \mathrm{Sr}$, relative to the non-radiogenic isotopes, will vary from the decay of the parent nuclide rubidium- $87\left({ }^{87} \mathrm{Rb}\right)$. Groundwater acquires dissolved $\mathrm{Sr}$ at the recharge area during infiltration and percolation, and along the flow path by dissolution of minerals or through ion exchange with such minerals as clays and zeolites. Thus, the ${ }^{87} \mathrm{Sr} /{ }^{86} \mathrm{Sr}$ isotopic ratio is not a conservative tracer, but instead provides an integrated flow-path signal of water-rock interaction. In this context, Boschetti et al. [13] present the ${ }^{87} \mathrm{Sr} /{ }^{86} \mathrm{Sr}$ ratio and $\mathrm{Sr}$ concentration data of the groundwater collected to-date in the different regions of Djibouti. This study aims to 
discriminate between the different water sources, to evaluate the water/rock ratio, and to compare the data with those coming from the groundwater in the neighboring Main Ethiopian Rift and the Red Sea bottom brine.

Radon $\left({ }^{222} \mathrm{Rn}\right)$ is an endogenous natural radioactive noble gas, and is a product of the decay chain of Uranium $\left({ }^{238} \mathrm{U}\right) .{ }^{222} \mathrm{Rn}$ (half-life of 3.82 days) is the most commonly occurring radon isotope in nature, produced by $\alpha$-decay from Radium $\left({ }^{226} \mathrm{Ra}\right)$. It is soluble in water, and its behavior and concentration in groundwater are strongly influenced by the geological nature of the substratum and by the occurrence of Rn parent elements. The most important processes for $\mathrm{Rn}$ transport in groundwater are diffusion and convection. Natural variations of $R n\left({ }^{222} \mathrm{Rn}\right)$ concentrations are the fundamental prerequisite of using this radioactive gas as a tracer, or even precursor, of natural processes, including earthquakes. Barberio et al. [14] used radon in groundwater from the Giardino Spring (Central Italy) and groundwater levels in the Sulmona plain (Central Apennines, Italy) to examine their cyclic and noncyclic variations. The substantial absence of the principal lunar components in the Rn groundwater concentration and groundwater level spectra reveals no correlations with gravitational (lunar) components of the solid Earth tide spectrum.

Instead, Avery et al. [15] used the concentration of naturally occurring ${ }^{222} \mathrm{Rn}$ and introduced xenon $(\mathrm{Xe})$ to formulate a water budget, and to quantify streamwater-groundwater interaction in the Martis Valley in California (USA). With this approach, Avery et al. [15] demonstrate that the influx of groundwater to the stream is heterogeneous and related to topographic or morphologic stream features. The Martis Valley is categorized as a medium priority by the California Statewide Groundwater Elevation Monitoring Program. With 128\% population growth in the 2000s and 90\% of water used being supplied from groundwater [15], understanding groundwater-surfacewater interaction in this basin is critical.

The last contribution [16] to this section is related the groundwater protection zone (GPZ) method as a methodological framework for defining and safeguarding zones of groundwater bodies in the Sierra de Cañete (Southern Spain). Hydrogeochemical and isotopic characterizations (i.e., water and dissolved elements such as sulfate) of groundwater were used as supporting tools to differentiate between sectors within aquifers. Jiménez-Madrid et al. [16] used sulfur isotopes $\left(\delta^{34} S\right)$ to identify the source of sulfate ions in the various sectors of the carbonate aquifer because the simple hydrochemical study was not enough to distinguish between a natural or anthropogenic origin.

\subsection{Tracing Pollution and Its Sources with Isotopes}

Naturally occurring isotope systems such as nitrogen and uranium are handy for characterizing sources of pollution, time scale tracers of natural processes, and producing background information.

Nitrate pollution in river systems is a worldwide problem that has gained widespread attention in the field of aquatic ecology. In recent years, economic development and anthropogenic activities have increased the concentration of nitrate in river systems, which has caused many environmental problems, such as the eutrophication of water, algal blooms, and low-oxygen zones.

Meng et al. [17] combined multi-isotope tracers $\left(\delta^{15} \mathrm{~N}-\mathrm{NO}_{3}{ }^{-}\right.$and $\left.\delta^{18} \mathrm{O}-\mathrm{NO}_{3}{ }^{-}\right)$, hydrochemical analysis, and the IsoSource model to identify the apportioning of nitrate sources in the Fenhe River system in Shanxi Province, China.

$\mathrm{Li}$ et al. [18] applied the same approach to the Taihu Lake, which is the third-largest freshwater lake in China. The outcomes of this study will be useful as reference values for reducing nitrate pollution in the inflowing rivers in the north of Taihu Lake.

Malov [19] analyzes the uranium redistribution in the sandstones and siltstones of aquifers of the Northern Dvina basin, a paleo-valley in Northwest Russia that is associated with the formation of increased concentrations of uranium in both rocks and groundwater. Malov highlights that, for groundwater under oxidizing conditions, an increase in the concentration of uranium is characteristic of an increase in the residence time (age) of water in the aquifer. Additionally, the ${ }^{234} \mathrm{U} /{ }^{238} \mathrm{U}$ activity ratio increases with the increasing radioactivity of groundwater. 
The last two manuscripts are related to groundwater contamination under emergency conditions such as a release or leak of the radioactive materials due to a nuclear accident scenario [20] and the complex management of sites contaminated with chlorobenzene [21].

Khayyun [20] provides a simulation of groundwater flow and advective-dispersive migration of radioactive $\mathrm{Co}-60$ through an aquifer with three layers, which release or leak into groundwater from the Active Metallurgy Testing Laboratory (LAMA) Nuclear Facility in Iraq, due to a nuclear accident.

Alberti et al. [21] apply compound-specific stable isotope analysis for investigation of the relationship between the up-gradient and down-gradient of the hydraulic barrier, and to target potential chlorobenzene biodegradation processes. The use of the concentration-weighted average $\delta^{13} \mathrm{C}$ of CBs + benzene was crucial in understanding how the plumes in the down-gradient of the hydraulic barrier are not connected with the up-gradient contamination.

\section{Conclusions}

Isotope hydrology is a genuinely interdisciplinary science. It was developed from the application of methods evolved in physics (analytical techniques) to problems of Earth and environmental sciences since around the 1950s. The classical tools of isotope hydrology are the isotopes of the elements of the water molecule $\left(\mathrm{H}_{2} \mathrm{O}\right)$ itself, namely, the rare stable isotopes of hydrogen and oxygen $\left({ }^{2} \mathrm{H}\right.$ and ${ }^{18} \mathrm{O}$ ) and the radioactive tritium $\left({ }^{3} \mathrm{H}\right)$. Later, many more methods were joined to the toolbox of isotope hydrologists.

Nineteen original research articles have been selected for this Special Issue. The driving force behind this Special Issue has been the need to point the hydrological and water resource management societies in the direction of up-to-date research and best practices.

A significant challenge is to use the variability as a signal with no noise; the isotopes and chemistry provide very detailed information about sources and reactions in shallow systems, and the challenge now is to develop appropriate models to use the data.

We believe that the collation of these papers contributes to exhort further interest in environmental tracers that can offer and be used to address substantive issues of vulnerability, sustainability, and uncertainty in groundwater resource management.

Acknowledgments: The Guest Editor (MB) thanks both the research community for offering and contributing a wide range of valuable papers, and the publisher MDPI for allocating resources and support towards this Special Issue.

Conflicts of Interest: The author declares no conflict of interest.

\section{References}

1. Nigro, A.; Sappa, G.; Barbieri, M. Boron isotopes in groundwater: evidence from contamination and interaction with terrigenous-evaporitic sequence, east-central Italy. Geochem. Explor. Environ. Anal. (GEEA) 2018, 18, 343-350. [CrossRef]

2. Nigro, A.; Sappa, G.; Barbieri, M. Boron isotopes and rare earth elements in the groundwater of a landfill site. J. Geochem. Explor. 2018, 190, 200-206. [CrossRef]

3. Chen, X.; Wang, G.; Wang, F. Classification of Stable Isotopes and Identification of Water Replenishment in the Naqu River Basin, Qinghai-Tibet Plateau. Water 2019, 11, 46. [CrossRef]

4. Mahindawansha, A.; Breuer, L.; Chamorro, A.; Kraft, P. High-Frequency Water Isotopic Analysis Using an Automatic Water Sampling System in Rice-Based Cropping Systems. Water 2018, 10, 1327. [CrossRef]

5. Peters, E.; Visser, A.; Esser, B.K.; Moran, J.E. Tracers Reveal Recharge Elevations, Groundwater Flow Paths and Travel Times on Mount Shasta, California. Water 2018, 10, 97. [CrossRef]

6. Guo, Q.; Zhou, Z.; Wang, S. The Source, Flow Rates, and Hydrochemical Evolution of Groundwater in an Alluvial Fan of Qilian Mountain, Northwest China. Water 2017, 9, 912. [CrossRef]

7. Shi, X.; Pu, T.; He, Y.; Qi, C.; Zhang, G.; Xia, D. Variability of Stable Isotope in Lake Water and Its Hydrological Processes Identification in Mt. Yulong Region. Water 2017, 9, 711. [CrossRef] 
8. Gao, H.; Ryan, M.C.; Li, C.; Sun, B. Understanding the Role of Groundwater in a Remote Transboundary Lake (Hulun Lake, China). Water 2017, 9, 363. [CrossRef]

9. Maruyama, S.; Kato, H. Identification of Waters Incorporated in Laguna Lake, Republic of the Philippines, Based on Oxygen and Hydrogen Isotopic Ratios. Water 2017, 9, 328. [CrossRef]

10. Yang, Y.; Li, B. Temporal and Spatial Variations of Hydrological Processes on the Landscape Zone Scale in an Alpine Cold Region (Mafengou River Basin, China): An Update. Water 2017, 9, 574. [CrossRef]

11. González-Trinidad, J.; Pacheco-Guerrero, A.; Júnez-Ferreira, H.; Bautista-Capetillo, C.; Hernández-Antonio, A. Identifying Groundwater Recharge Sites through Environmental Stable Isotopes in an Alluvial Aquifer. Water 2017, 9, 569. [CrossRef]

12. Wang, X.; Qiao, W.; Chen, J.; Liu, X.; Yang, F. Understanding the Burial and Migration Characteristics of Deep Geothermal Water Using Hydrogen, Oxygen, and Inorganic Carbon Isotopes. Water 2018, 10, 7. [CrossRef]

13. Boschetti, T.; Awaleh, M.O.; Barbieri, M. Waters from the Djiboutian Afar: A Review of Strontium Isotopic Composition and a Comparison with Ethiopian Waters and Red Sea Brines. Water 2018, 10, 1700. [CrossRef]

14. Barberio, M.D.; Gori, F.; Barbieri, M.; Billi, A.; Devoti, R.; Doglioni, C.; Petitta, M.; Riguzzi, F.; Rusi, S. Diurnal and Semidiurnal Cyclicity of Radon $\left({ }^{222} \mathrm{Rn}\right)$ in Groundwater, Giardino Spring, Central Apennines, Italy. Water 2018, 10, 1276. [CrossRef]

15. Avery, E.; Bibby, R.; Visser, A.; Esser, B.; Moran, J. Quantification of Groundwater Discharge in a Subalpine Stream Using Radon-222. Water 2018, 10, 100. [CrossRef]

16. Jiménez-Madrid, A.; Castaño, S.; Vadillo, I.; Martinez, C.; Carrasco, F.; Soler, A. Applications of Hydro-Chemical and Isotopic Tools to Improve Definitions of Groundwater Catchment Zones in a Karstic Aquifer: A Case Study. Water 2017, 9, 595. [CrossRef]

17. Meng, Z.; Yang, Y.; Qin, Z.; Huang, L. Evaluating Temporal and Spatial Variation in Nitrogen Sources along the Lower Reach of Fenhe River (Shanxi Province, China) Using Stable Isotope and Hydrochemical Tracers. Water 2018, 10, 231. [CrossRef]

18. Li, D.; Jiang, X.; Zheng, B. Using $\delta^{15} \mathrm{~N}$ and $\delta^{18} \mathrm{O}$ Signatures to Evaluate Nitrate Sources and Transformations in Four Inflowing Rivers, North of Taihu Lake. Water 2017, 9, 345. [CrossRef]

19. Malov, A.I. Evolution of Uranium Isotopic Compositions of the Groundwater and Rock in a Sandy-Clayey Aquifer. Water 2017, 9, 910. [CrossRef]

20. Khayyun, T.S. Simulation of Groundwater Flow and Migration of the Radioactive Cobalt-60 from LAMA Nuclear Facility-Iraq. Water 2018, 10, 176. [CrossRef]

21. Alberti, L.; Marchesi, M.; Trefiletti, P.; Aravena, R. Compound-Specific Isotope Analysis (CSIA) Application for Source Apportionment and Natural Attenuation Assessment of Chlorinated Benzenes. Water 2017, $9,872$. [CrossRef]

(C) 2019 by the author. Licensee MDPI, Basel, Switzerland. This article is an open access article distributed under the terms and conditions of the Creative Commons Attribution (CC BY) license (http://creativecommons.org/licenses/by/4.0/). 